\title{
Comparison of mathematical models of maturation rate of the airborne Venturia inaequalis (Cooke) Wint. ascospores in central Poland
}

\author{
Paweł Jankowski ${ }^{1}$ [D Sylwester Masny ${ }^{2}$
}

Received: 8 October 2018 / Accepted: 7 May 2019 / Published online: 22 May 2019

(c) The Author(s) 2019

\begin{abstract}
Models of maturation rate of the airborne Venturia inaequalis (Cooke) Wint. ascospores were compared using field data collected from spore traps in Skierniewice, Poland, during 2005-2008 and 2010-2014. Two sets of models describing ascospores maturation rate as a function of cumulative temperature were compared. The first set consisted of the "Stensvand" model with degrees summed during and $147 \mathrm{~h}$ after the rainfall, and the "Only" type models accumulating temperature only during hours with observed high moisture level indicated by rain, leaf wetness or high humidity. The second set consisted of more complex "All" type models proposed in the study, with degrees summed each hour, but differently weighted for periods with various sources of moisture such as rain, leaf wetness (LW) and relative air humidity (RH). The "All" type models proved to be superior over the "Only" type models. The "All Rain + LW + RH," "All Rain + LW," "All LW" and the "Stensvand" models gave the best match with the data. The final and most important result of the study is such that all of the examined models had high and unsatisfactory range of models' uncertainty for the data from central Poland. Therefore, further improvements in modeling of ascospore maturation rate are necessary. Low accuracy of the models limits their practical application at the current stage of development.
\end{abstract}

Keywords Venturia inaequalis · Apple scab · Ascospore maturation · Mathematical model $\cdot$ Temperature accumulation · Influence of moisture

\section{Introduction}

Apple scab, caused by the fungal pathogen Venturia inaequalis (Cooke) Wint., is the most harmful apple disease in temperate regions throughout the world (MacHardy 1996). It may lead to significant economic losses to the growers due to reduction in fruit quantity and fruit quality. $75 \%$ of

Electronic supplementary material The online version of this article (https://doi.org/10.1007/s41348-019-00229-5) contains supplementary material, which is available to authorized users.

Paweł Jankowski

pawel_jankowski@sggw.pl

1 Department of Econometrics and Statistics, Faculty of Applied Informatics and Mathematics, Warsaw University of Life Sciences - SGGW, Ul. Nowoursynowska 159, 02-776 Warsaw, Poland

2 Department of Phytopathology, Research Institute of Horticulture, Ul. Konstytucji 3 Maja 1/3, 96-100 Skierniewice, Poland the pesticide use in apple production is related to the control of fungal diseases, where apple scab has a share of $70 \%$ (Creemers and van Laer 2006), applied in a few to over a dozen fungicide treatments in the growing season. High amount of fungicides used in horticultural production has negative impact on the environment (Wightwick et al. 2010).

There are various approaches to limit the number of sprays in modern orchards. The key one is to reduce overwintering inoculums by autumn mulching or ranking leaves in the orchard. The presented study is focused on an approach based on mathematical modeling used to predict the risk of a $V$. inaequalis ascospore release and following infection. Fungicide programs have been developed on the basis of this approach (Gadoury et al. 1989; Rossi et al. 2007). In order to predict ascospore releases, first their seasonal maturation pattern is described as a function of cumulative temperature. The major factor accelerating ascospore development is moisture. Its influence on ascospore development ratio is included in definition of cumulative temperature. Various definitions of temperature accumulation were proposed in mathematical 
models of ascospore maturation examined by many groups of researchers in many countries (Massie and Szkolnik 1974; James et al. 1981; Gadoury and MacHardy 1982; James and Sutton 1982a, b; MacHardy and Gadoury 1985; Stensvand 1993; Beresford 1999; Rossi et al. 1999, 2000; Gadoury et al. 2004; Stensvand et al. 2005; Schwabe et al. 1989; Alves and Beresford 2013; Roubal and Nicot 2016).

To date, no results of modeling of ascospore maturation have been reported on from Poland though Poland became in the recent years the largest producer of apples in the European Union and third largest in the world (FAOSTAT 2018).

The aim of the study was to compare effectiveness of various models, using different definitions of cumulative temperature, in describing the development of $V$. inaequalis (Cooke) Wint. ascospores in central Poland.

\section{Materials and methods}

\section{Ascospore trapping and weather data}

The experiment was conducted at the Experimental Orchard of the Research Institute of Pomology and Floriculture in Skierniewice, Poland (N51 $55^{\prime}$; E20 $6^{\prime}$ '), over ten consecutive years, from 2005 to 2014 . Weather conditions were recorded by an automatic weather station (model MetosCompact, Pessl Instruments, Weiz, Austria) placed at the experimental site.

A Burkard 7-day recording volumetric spore trap (Burkard Manufacturing Co Ltd., Rickmansworth, Hertfordshire, UK) was used to monitor the release of ascospores. Approximately $2 \mathrm{~m}^{2}$ of the orchard floor under the Burkard sampler were covered with leaves of the apple cultivar McIntosh heavily infected with $V$. inaequalis the previous season. The trees were not treated with fungicides during the experiment and for the preceding 10 years. The spore trap was installed in the center of this area and was adjusted to sample the air $1 \mathrm{~m}$ above the ground at a sampling rate of $0.6 \mathrm{~m}^{3} \mathrm{~h}^{-1}$. The tape from the Burkard trap, covered with a thin layer of Gelvatol and Vaseline, was changed weekly and cut into daily segments $(48 \mathrm{~mm}$ long). The number of $V$. inaequalis ascospores deposited on the sampling surface was counted under a microscope (200x) by scanning two equidistant transects across the tape's long axis at $2 \mathrm{~mm}$ intervals, which corresponded to a time interval of $1 \mathrm{~h}$.

The release data were analyzed on an hourly scale. A discharge terminated when it was followed by $4 \mathrm{~h}$ without trapped ascospores.

The ascospore discharge seasons in the years 2005-2014 lasted from 43 to 93 days with the first and last dates of spore releases varying from March 12 to April 19 and from May 29 to June 17, respectively. The ascospores were trapped during 21-33 days of a season, giving in total 256 discharges. Graphs presenting the cumulated proportion of trapped ascospores in each examined season are shown in Supplementary Figure 1.

Graphs presenting the main weather factors, precipitation, leaf wetness duration, average relative humidity and average temperature, calculated for each day since March 1 to June 15, in the years 2005-2014, are shown in Supplementary Figures 2-15, respectively. The graph of leaf wetness in year 2009 suggests incorrect measurements of the leaf wetness sensor in this season: in two periods of the year, April 8-22 and May 15-June 5, the sensor measured constant leaf wetness. Such incorrect data caused the problem of overfitting the data in all models in which leaf wetness was applied as one of the indicators of moisture level in the orchard. Therefore, data from the year 2009 were excluded from the analysis.

\section{General assumptions of the models of ascospore maturation examined in the study}

The numbers of mature ascospores in the experimental orchard were approximated with the numbers of airborne ascospores trapped during consecutive discharges with a Burkard-type trap (Rossi et al. 1999; Lacey and West 2006). The spores, which by being released into the air can lead to apple scab infection in the orchard, were accepted as mature.

The usually applied time scale for a description of ascospore maturation is the daily scale. Then, a number of observed ascospores are calculated for each day of the season. In the current study, the hourly scale was used as it should more accurately reflect the development of ascospores in response to changes in weather (James and Sutton 1982b).

The cumulative proportion (percentage) $p$ of mature ascospores observed to the present moment of the season to the total number of ascospores trapped during the entire season was modeled. The increasing from 0 to 1 proportion of mature ascospores was described as a function of the cumulative temperature ( $T_{\text {cum }}$ ) being the sum of the positive temperatures in the hours counted from the starting date referred to as biofix (Massie and Szkolnik 1974). The biofix was established as the green tip stage of the apple trees in the experimental orchard. In the case of the years in which the first ascospore discharge was observed before the date of the green tip, the date of the first discharge was applied for the biofix.

From the beginning of modeling of the ascospore development dynamics, various authors recognized that moisture is the limiting factor for pseudothecial development of $V$. inaequalis. The pseudothecial development is correlated with the level of rainfall or relative humidity (Massie and Szkolnik 1974; James and Sutton 1982a). In order to account for the influence of moisture level on temperature accumulation, weights can be added to the simplest definition of $T_{\text {cum }}$, related to weather factors. In the case of the hourly scale, the general form of $T_{\text {cum }}$ is: 
$T_{\text {cum }}(h)=T_{\text {cum }}(h-1)+\gamma \cdot T(h)$

where $T_{\text {cum }}(h)$ is the cumulative temperature in the hour $h$ counted from the biofix and $T(h)$ and $\gamma$ are the average temperature and the weight function in hour $h$, respectively. Various definitions of $T_{\text {cum }}$ were tested in the literature, but to the best of our knowledge, in all models it has been assumed that $\gamma=1$ if moisture level is high and $\gamma=0$ otherwise. The indicators of moisture used were precipitation, leaf wetness (LW), high relative humidity (RH) or the presence of dew. In the current study, a few sets of models with different definitions of $\gamma$ were examined.

In all examined models, the probit function was applied to describe the dependence of the cumulative proportion of mature ascospores on cumulative temperature:

$\operatorname{probit}\left(p\left(T_{\text {cum }}\right)\right)=\operatorname{probit}\left(T_{\text {cum }}\right)=\Phi^{-1}\left(p\left(T_{\text {cum }}\right)\right)$,

were $\Phi^{-1}$ is the inverse of the cumulative distribution function of the standard normal distribution. Probit function was represented as a linear function of the cumulative temperature:
Additional parameters, denoted as $\gamma$, were used in some of the examined models. These parameters were contained in the definitions of the cumulative temperature applied in these more complex models. In this case also, such values of the $\beta_{0}, \beta_{1}$ and $\gamma$ coefficients were found, for which the sum of squared errors of prediction, SSE, of formula (4), is minimal. The values of the parameters were found in two repeated steps. First, the values of the cumulated temperature were calculated for all experimental points with some set of the values of the $\gamma$ parameters. Next, the probit function of formula (3) was fitted to the experimental data using simple linear regression. The two steps were repeated within the variable metric optimization algorithm (for code description see (Nash 1990)) until the algorithm found such values of the parameters $\beta_{0}, \beta_{1}$ and $\gamma$, for which SSE is minimal. The obtained results were cross-checked with application of the Newton-type algorithm (Dennis and Schnabel 1983).

The quality of a model fit was evaluated using SSE and the coefficient of determination, $R^{2}$ :

$$
\begin{aligned}
R^{2}= & \sum_{i=1}^{n}\left(\operatorname{probit}\left(T_{\text {cum }_{i}}\right)_{\text {observed }}-\operatorname{probit}\left(T_{\text {cum }_{i}}\right)_{\text {predicted }}\right)^{2} / \sum_{i=1}^{n} \operatorname{probit}\left(T_{\text {cum }_{i}}\right)_{\text {observed }} \\
& -\overline{\operatorname{probit}\left(T_{\text {cum }_{i}}\right)_{\text {observed }}}
\end{aligned}
$$

$\operatorname{probit}\left(T_{\text {cum }}\right)=\beta_{0}+\beta_{1} \cdot T_{\text {cum }}$

\section{Statistical analysis}

\section{Fitting models of ascospore maturation to experimental data}

Models of ascospore maturation were fitted to the experimental data with two methods. The optimal values of the $\beta_{0}$ and $\beta_{1}$ coefficients (formula (3)), in the models where these parameters were the only ones used, were computed with linear regression. In this approach, such values of the $\beta_{0}$ and $\beta_{1}$ coefficients are found, for which the sum of squared errors of prediction (SSE) is minimal. The SSE function is defined as:

$\mathrm{SSE}=\sum_{i=1}^{n}\left(\operatorname{probit}\left(T_{\text {cum }_{i}}\right)_{\text {observed }}-\operatorname{probit}\left(T_{\text {cum }_{i}}\right)_{\text {predicted }}\right)^{2}$

where $i$ numbers the ascospore releases and $n$ is their total number in the dataset, $\operatorname{probit}\left(T_{\text {cum }_{i}}\right)_{\text {observed }}$ and $\operatorname{probit}\left(T_{\text {cum }_{i}}\right)_{\text {predicted }}$ are the experimentally observed and predicted by the model values of the probit function for the ascospore discharge $i$, respectively. where $\overline{\operatorname{probit}\left(T_{\text {cum }_{i}}\right)_{\text {observed }}}$ is the mean of the probit values in the dataset used in the model's fit.

The 99\% uncertainty bands of the models were calculated using the Working-Hotelling procedure (Working and Hotelling 1929).

\section{Validating and comparing models of ascospore maturation}

The leave-p-out cross-validation method was applied (Shao 1993) to compare the quality of various models of ascospore maturation, based on fits to the experimental data from years 2005-2008 and 2010-2014. The method involved splitting the dataset into two parts- the training part (used to match the model parameters) and the validation part (used to test the model fits quality). Each possible splitting of the data into two sets was examined. In the case of the 10 years dataset, three methods were used:

1. Leave 1-out: 9 different datasets-in each of these the data were split into a training set containing observations from 8 years and the validation set containing data from the one remaining season, 
2. Leave 2-out: 36 different datasets-in each of these the data were split into a training set containing observations from 7 years and the validation set containing data from the two remaining seasons,

3. Leave 3-out: 84 different datasets_-in each of these the data were split into a training set containing observations from 6 years and the validation set containing data from the three remaining seasons.

An exemplary leave 2-out dataset is a training set containing data from the years 2005, 06, 08, 11, 12, 13 and 14, and a validation set containing data from the years 2007 and 10 .

For each splitting of the data, the optimal values of the model parameters were calculated by matching the model to the data included in the training set. Then, using these values, for each splitting of the data, two Chi-squared values indicating how well the model described the data were computed. The first value was calculated for the training set: values of the probit function for the ascospore releases included in the training set, as predicted by the model, were compared with the probit values observed in the experiment. The second value was calculated for the validation set; likewise, the predicted probit values for the validation data were compared with the corresponding experimental values.

The comparison of ascospore development models was performed independently for the three p-out methods. In a given method, for each model, we calculated two values summarizing effectiveness of the model: the total Chi-squared of the training datasets, as the sum of the Chi-squares obtained for the 9, 36, or 84 training datasets, and similarly the total Chi-square of the validation datasets. Both calculated sums should be as small as possible. In the training data case, it indicates that the model can well describe the data used for its optimization. In the validation data case, it demonstrates that the model can also describe data that has not been used to optimize its parameters. If the sum of Chi-squares of the training data is low and the sum of Chi-squares of the validation data is high, it shows that the studied model tends to over-fit the data, i.e., matching its parameters only to the training data without the ability to describe data from other years at the same time. Such a model has no predictive value and should be rejected.

\section{Data analysis}

All analyzes presented in the study were performed in the $\mathrm{R}$ program version 3.4.3 (R Core Team 2018) with the use of RStudio version 1.1.419 (RStudio Team 2018).

\section{Results}

\section{Step one of model comparison}

The comparison of effectiveness of various models of ascospore maturation started with the models appearing in the topic literature. The basic model, used as a reference for other models, was the "New Hempshire" model of Gadoury and MacHardy (1982), in which the temperature is accumulated in every hour, regardless of weather conditions. In other models, accumulation of temperature was limited to the hours when high moisture level was observed. Due to temperature summation only in selected hours, the models were denoted as the "Only" models.

In the "Only Rain," "Only LW," and "Only RH" models temperature was accumulated solely in the hours when the rainfall was greater than $0 \mathrm{~mm}$, the leaf wetness was observed, or the relative humidity was higher or equal $85 \%$. Such RH limit value was inspired by the RH threshold first by James and Sutton (1982b) and later by other authors (Schwabe et al. 1989; Rossi et al. 1999). Additionally, the results of the "Only RH" model were compared for the possible values of $\mathrm{RH}$ between $1 \%$ and $99 \%$. It was found that the best fit to the data was obtained for $\mathrm{RH}$ in the range between 48 and $52 \%$ and the value $50 \%$ was selected for model tests.

In the "Stensvand" model, the temperature was summed in rainy hours and during $147 \mathrm{~h}$ afterward. To adjust the results of the "New Hempshire" model to periods of protracted dryness, which lead to slow down of ascospore maturation, Stensvand et al. (1998) proposed to halt temperature accumulation each time when no precipitation has been observed for a few previous days. From the other point of view, in comparison with the "Only Rain" model, the period in which model assumes ascospore maturation after each rainfall was extended in the "Stensvand" model to $147 \mathrm{~h}$. The limit of $147 \mathrm{~h}$ was selected in the study after comparison of the model results for a range of possible limit values.

Comparison of the results of the "Only Rain," "Only LW" and two "Only RH" models, with the RH threshold equal to $85 \%$ and $50 \%$, is presented in Table 1 . The results of fits and their validation showed that the relative air humidity was the indicator of moisture level giving the best description of the data, provided that low RH threshold of $50 \%$ was chosen. This model improved the "basic" "New Hempshire" model results. The "Only" type models including two wetness factors, models "Only Rain + LW" and "Only Rain + RH," or the "Only Rain + LW + RH" model, in which cumulative temperature increased if either rain, leaf wetness, or relative 
Table 1 Comparison of the ascospore maturation models for the data from the years 2005-2008 and 2010-2014

\begin{tabular}{|c|c|c|c|c|c|c|c|c|c|c|c|}
\hline \multirow[t]{2}{*}{ Model } & \multicolumn{2}{|l|}{ 1-out } & \multicolumn{2}{|l|}{ 2-out } & \multicolumn{2}{|l|}{ 3-out } & \multicolumn{5}{|c|}{9 years } \\
\hline & Train & Valid & Train & Valid & Train & Valid & SSE & $R^{2}$ & $\gamma_{1}$ (Rain) & $\gamma_{2}(\mathrm{LW})$ & $\gamma_{3}(\mathrm{RH})$ \\
\hline New Hempshire & 1.36 & 0.202 & 4.69 & 1.63 & 9.22 & 5.79 & 0.171 & 85.2 & - & - & - \\
\hline Only Rain & 1.69 & 0.239 & 5.87 & 1.93 & 11.6 & 6.86 & 0.213 & 81.6 & - & - & - \\
\hline Only LW & 1.55 & 0.247 & 5.34 & 2.00 & 10.4 & 7.15 & 0.197 & 83.0 & - & - & - \\
\hline Only RH [50\%] & 1.27 & 0.177 & 4.40 & 1.42 & 8.70 & 5.04 & 0.159 & 86.2 & - & - & - \\
\hline Only RH [85\%] & 1.84 & 0.265 & 6.36 & 2.14 & 12.5 & 7.60 & 0.232 & 80.0 & - & - & - \\
\hline Stensvand [147 h] & 1.06 & 0.148 & 3.67 & 1.19 & 7.26 & 4.21 & 0.133 & 88.5 & - & - & - \\
\hline All Rain & 1.09 & 0.165 & 3.77 & 1.34 & 7.40 & 4.77 & 0.138 & 88.1 & 11.8 & - & - \\
\hline All LW & 0.895 & 0.141 & 3.09 & 1.15 & 6.06 & 4.09 & 0.113 & 90.2 & - & 5.52 & - \\
\hline All RH [85\%] & 1.21 & 0.206 & 4.17 & 1.73 & 8.18 & 6.31 & 0.154 & 87.7 & - & - & 2.17 \\
\hline All Rain + LW & 0.897 & 0.150 & 3.08 & 1.22 & 6.03 & 4.36 & 0.114 & 90.2 & 3.60 & 6.14 & - \\
\hline All Rain + RH [85\%] & 1.04 & 0.189 & 3.54 & 1.54 & 6.85 & 5.52 & 0.132 & 88.6 & 13.1 & - & 2.02 \\
\hline All Rain + LW + RH [85\%] & 0.880 & 0.161 & 3.01 & 1.30 & 5.87 & 4.69 & 0.112 & 90.3 & $\begin{array}{l}3.99 \\
\gamma_{1}(\text { Rain })\end{array}$ & $\begin{array}{l}7.08 \\
\gamma_{2}\left(\operatorname{Rain}^{2}\right)\end{array}$ & 1.68 \\
\hline All proportional rain linear & 1.184 & 0.182 & 4.08 & 1.47 & 8.01 & 5.21 & 0.150 & 87.1 & 8.02 & - & - \\
\hline All proportional rain quadratic & 1.125 & 0.170 & 3.88 & 2.45 & 7.60 & 13.7 & 0.142 & 87.7 & 11.9 & -0.201 & - \\
\hline
\end{tabular}

Leave-p-out cross-validation methods 1-out, 2-out and 3-out were applied and the SSE values for the training (train) and validation (valid) sets of data are presented. Additionally, models' fits to the full set of 9 years data shown: SSE, the coefficient of determination and adequate model parameters $\gamma_{i}$. All SSE values are given in thousands. The values of the RH limit in the models indicated. In the "Stensvand" model, the temperature was summed in rainy hours and during $147 \mathrm{~h}$ afterward

humidity indicated the presence of high moisture level, did not further improve the fit results (results not shown).

The best description of the observations from central Poland among this group of models was obtained with the "Stensvand" model.

\section{Step two of model comparison}

In this step of analysis, we examined newly introduced models. The models accumulated temperature in each hour of the season and therefore were designated as "All" type models. The effect of moist periods was introduced by multiplying the temperatures in the moist hours by extra weights. An exemplary definition of the cumulative temperature, in the most complex of tested approaches, the "All Rain + LW + RH" model, is following:

- If high moisture level is not observed: $T_{\text {cum }}(h)=T_{\text {cum }}(h-1)+T(h)$

- Otherwise, in the presence of rain: $T_{\text {cum }}(h)=T_{\text {cum }}(h-1)+\gamma_{1} \cdot T(h)$,

- Otherwise, in the presence of leaf wetness: $T_{\text {cum }}(h)=T_{\text {cum }}(h-1)+\gamma_{2} \cdot T(h)$

- Otherwise, in the presence of high relative humidity: $T_{\text {cum }}(h)=T_{\text {cum }}(h-1)+\gamma_{3} \cdot T(h)$.

The coefficients $\gamma_{1}, \gamma_{2}$ and $\gamma_{3}$ are the weights assigned to precipitation, leaf wetness and high relative humidity
(RH $\geq 85 \%)$, respectively, and the weight of dry hours is 1 . The rainfall was used as the primary factor for ascospores maturation in the described models. The second factor was the leaf wetness and the last one was the high relative humidity. The change in the RH threshold did not improve the quality of the models' fits.

The results presented in Table 1 showed that the "All" type models better described the data than the corresponding "Only" type models with the same indicators of moisture level. For the "All" type models with a single indicator of moisture level, the best data description was obtained in the "All LW" model. The quality of its fit and validation was better than that of the "New Hempshire" model and the "Stensvand" model.

The inclusion of additional indicators of moisture level did not significantly improve matching of models, and though the "All Rain + LW + RH" model gave the best fit to the data among all models tested in the study, validation results for this model were slightly worse than for the least complicated "All Rain + LW" model, with similar goodness of fit.

\section{Step three of model comparison}

In the "Only" and "All" models, the very fact of rain observation was used as the indicator of moisture level. In this step, two additional "All" type models, in which the temperature accumulated in the rainy hours was multiplied 

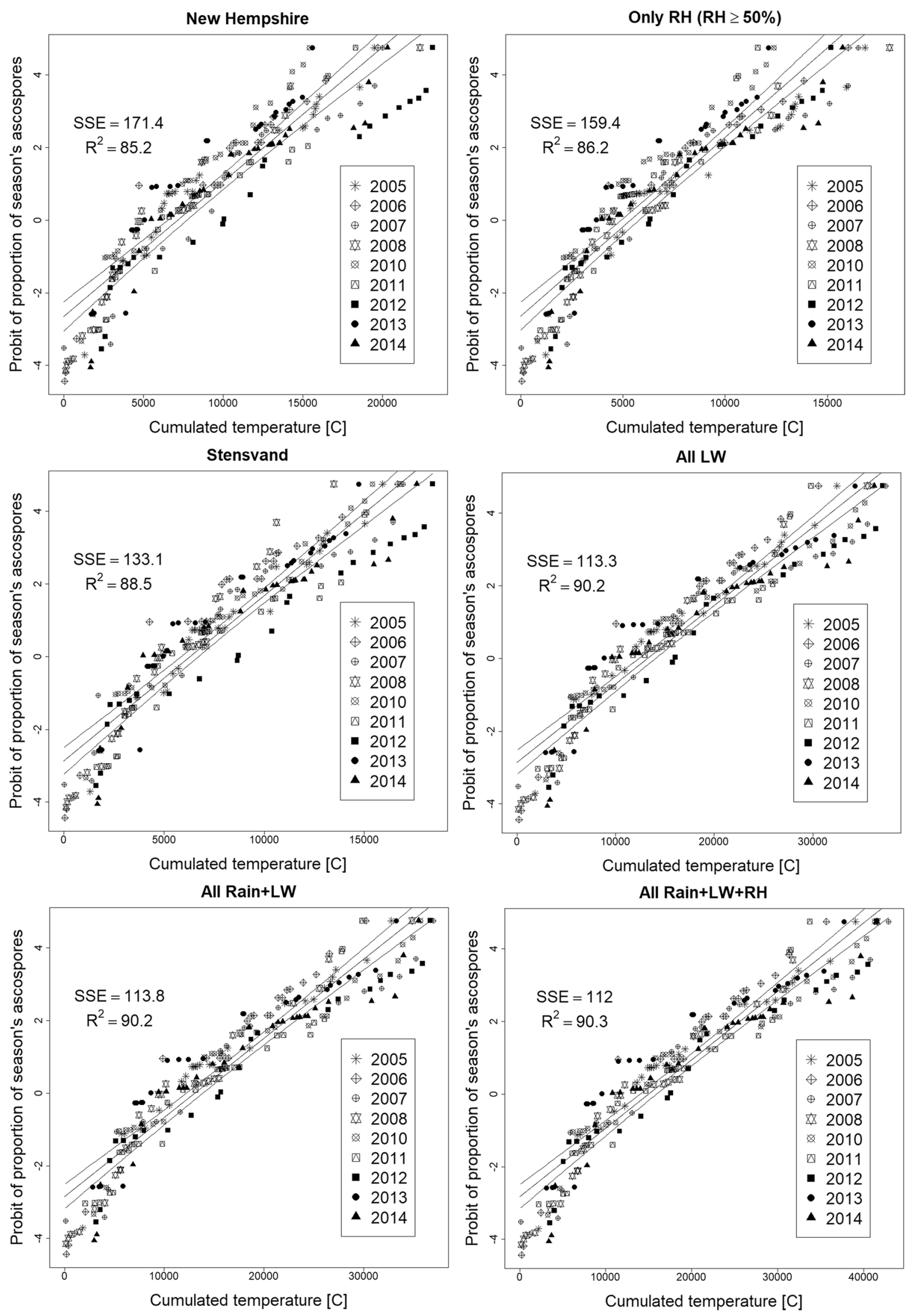
4 Fig. 1 Probit of the cumulative proportion of the season's ascospores of $V$. inaequalis. Fits of the ascospore maturation models, "New Hempshire," "Only RH" with the RH threshold equal to 50\%, "Stensvand," "All LW," "All Rain + LW" and "All Rain + LW + RH," to the data from the years 2005-2008 and 2010-2014. In each plot, the best fit is given by the central line and $99 \%$ model uncertainty by the upper and lower lines

by the amount of precipitation (in $\mathrm{mm}$ ), were tested. The advantage of such approach is that it allowed to examine both the linear and the quadratic relation between the rate of ascospore maturation and hourly precipitation. The tested models were labeled as the "All Proportional Rain linear" and "All Proportional Rain quadratic" models, respectively. The cumulative temperature was defined as:

- If high moisture level is not observed: $T_{\text {cum }}(h)=T_{\text {cum }}(h-1)+T(h)$

- Otherwise, in the presence of rain:

- "All Proportional Rain linear": $T_{\text {cum }}(h)=T_{\text {cum }}(h-1)+\gamma_{1}$ -Rain $(h) \cdot T(h)$,

- "All Proportional Rain quadratic": $T_{\text {cum }}(h)=T_{\text {cum }}(h-1)+\gamma_{1} \cdot \operatorname{Rain}(h) \cdot T(h)+\gamma_{2} \cdot \operatorname{Rain}(h)^{2} \cdot T(h)$,

where $\operatorname{Rain}(h)$ is the rainfall in the hour $h$.

The results presented in Table 1 showed that using the amount of precipitation as the indicator of moisture level did not improve the fit results of the "All Rain" model.

\section{Fitting models to full set of data}

The numerical results of model fits to the full set of data from the years 2005-2008 and 2010-2014 are presented in Table 1. A graphical representation of the selected model fits, along with the uncertainty intervals, is shown in Figs. 1 and 2, for the probit of the cumulative proportion and the cumulative proportion of the season's ascospores of $V$. inaequalis. The charts show the results of the models with the best goodness of fit: the "New Hempshire," the "Only RH" with the RH threshold of 50\%, and the "Stensvand" models as representatives of the models known from the literature of topic; the "All LW," the "All Rain + LW" and the "All Rain + LW + RH" models as the representatives of the models proposed in this study. The models accuracy is low. Though the $99 \%$ uncertainty bands were calculated, they do not contain a large part of the experimental points.

\section{Discussion}

The models examined in the first step of comparison applied either the same or analogous assumptions as the models presented and tested by other authors. The "Stensvand" model best described experimental data, correcting the results of the basic "New Hempshire" model. Hence, alike in the Norwegian climate conditions (Stensvand et al. 2005), extending the period of ascospore maturation after each rainfall improves the mathematical description of ascospore development in central Poland. Importantly, there is no significant difference between the results of Stensvand et al. (2005) and the current study in the length of the period after a rain during which the temperature was accumulated: 7 days versus $147 \mathrm{~h}$ (6 days and $3 \mathrm{~h})$. On the other hand, the examined "Only" type models which limited the ascospore maturation solely to the periods with observed high moisture level, indicated by rain occurrence, leaf wetness or high relative humidity with $\mathrm{RH} \geq 85 \%$, did not improve the "New Hempshire" model fits to the data. The only exception was the "Only RH" model with the RH threshold equal to 50\%. The difference between the two compared "Only RH" models was the number of hours of the season, during which the relative air humidity was below the RH threshold. In the case of $\mathrm{RH} \geq 85 \%$ such hours accounted for $49 \%$ and in the case of $\mathrm{RH} \geq 50 \%$ for $86 \%$ of all hours in the examined seasons. Therefore, the latter model resembles the main feature of the "Stensvand" model: It halts temperature accumulation in the most dry periods of the season. In weather conditions of central Poland, the RH threshold equal to $85 \%$ appears to be too high for such a purpose. For comparison, the hours which temperatures were accumulated in the "Stensvand" model accounted for $86 \%$ of all hours in the season. Finally, the proportions of rainy hours and hours with leaf wetness were about $7 \%$ and $25 \%$, respectively.

The above results agree with the results presented by Schwabe et al. 1989 for the South African data. Two models were compared in that study. First model based on the "New Hampshire" approach and second based on the approach proposed by James and Sutton (1982b), where temperature accumulation was limited to rainy days or days with at least $12 \mathrm{~h}$ of $\mathrm{RH} \geq 85 \%$. The second model, with analogous assumption to the "Only Rain + RH," gave worse goodness of fit to the data than the simple "New Hempshire" like approach. On the other hand, the model comparison results seem to disagree with the outcome of Rossi et al. (1999) for the climate conditions of the Po Valley in Northern Italy. In that study, the "Stensvand" and "Only Rain" type models both gave worse agreement with the data than the "New Hempshire" model. The results were improved by the model accumulating daily temperatures weighted with the approximated number of daily hours with wet leaves. That model was similar to the "Only LW" model tested in this study as both took into account the impact of leaf wetness on ascospore development. Similar goodness of fits was obtained with the model accumulating degrees on days with observed rainfall or dew deposition. The best fit to the data gave the approach combining effect of rain and high RH, analogously to the "Only Rain + RH" model. In 

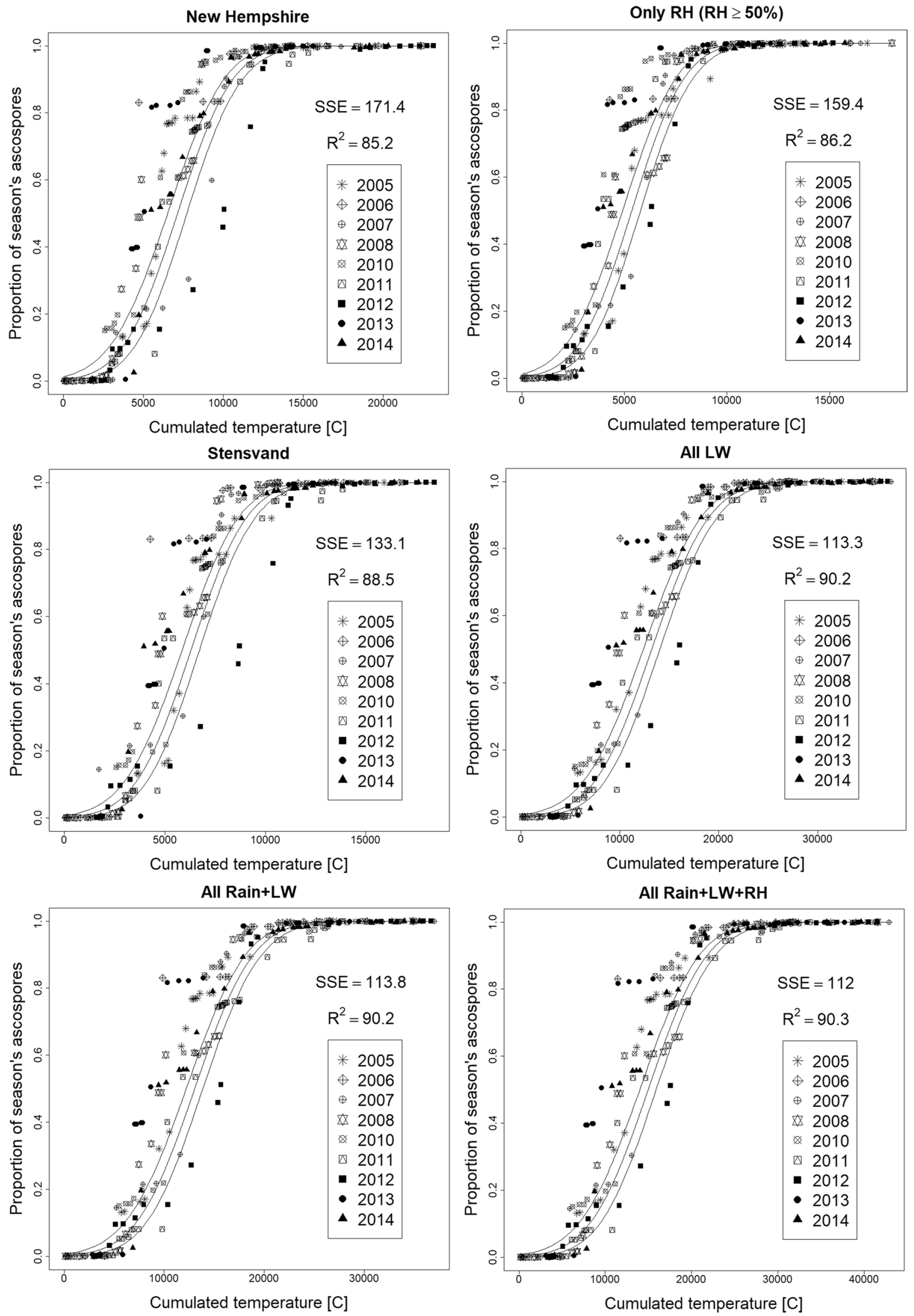
4 Fig. 2 Cumulative proportion of the season's ascospores of $V$. inaequalis. Fits of the ascospore maturation models, "New Hempshire," "Only RH" with the RH threshold equal to 50\%, "Stensvand," "All LW," "All Rain + LW" and "All Rain + LW + RH," to the data from the years 2005-2008 and 2010-2014. In each plot, the best fit is given by the central line and $99 \%$ model uncertainty by the upper and lower lines

the approach by Rossi et al. (1999), the degrees of rainy days and of the days when the relative humidity was equal to or higher than $85 \%$ for at least $8 \mathrm{~h}$ were accumulated. Finally, the model chosen by Rossi and coauthors as the best model to use in the regional warning system for apple scab management in Northern Italy (Rossi et al. 2000, 2007) was again analogous to the "Only LW" model examined in this study. Unlike in other models, in that approach, the hourly time scale was used in the $T_{\text {cum }}$ definition: The degrees were accumulated only in the hours when the leaves were wet. The model proved to better describe the experimental data in comparison with the "New Hempshire" model also in the case of analysis performed for the data from the Southern Brazil (Alves and Beresford 2013).

The "All" type models examined in the second step of analysis cannot be directly linked with the models presented so far in the literature. Though the acceleration of the ascospore maturation during the hours with observed high moisture level was considered in these approaches, similarly to the previously discussed models, the degrees were accumulated at every hour. The impact of moisture on the ascospore development was obtained by multiplying the temperatures summed during the wet hours by the weights corresponding to various sources of moisture. Therefore, on the one hand, the "All" type models include the main feature of the "New Hempshire" model, as they accumulate temperature during the season regardless of the weather. On the other hand, they express the difference between the ascospore maturation during the dry and wet periods of the season, similarly to other models from the literature of the topic.

Each of the "All" type models with one indicator of moisture level was superior to the corresponding "Only" type model. That confirms the importance of temperature accumulation during dry periods, first indicated by very good results of the "Stensvand" approach, where the prolonged effect of high moisture is taken into account by summing temperatures over a fixed dry period after each rainfall. Additionally, the results of the "All RH" model were not significantly influenced by the choice of the threshold value of RH. That seems to confirm the role of that threshold in the "Only RH" model: to halt temperature accumulation in the most dry periods of the season. In the "All RH" model, temperature is cumulated during whole season and accumulation only becomes faster when RH exceeds the limiting value. The best data description among the "All" type models with a single indicator of moisture level was obtained for the leaf wetness. The goodness of this fit was better than for the "Stensvand" model. The inclusion of multiple indicators of moisture level only slightly improved fit goodness of the "All LW" type model, and the "All Rain + LW + RH" approach gave the best fit to the data among all models tested in the study.

Can one further improve the "All" type models combining their features with the features of the "Stensvand" approach? Unlike in the "Stensvand" model, in the "All" type models the prolonged effect of high moisture level during the dry periods was not taken into account, in the sense that temperatures in such periods are not cumulated with the same weights as the temperatures during rain, observed leaf wetness or high RH. Therefore, the further improvement in the "All" type models seems possible. This would, however, mean a very high level of model complexity. On the other, the "All" type models sum temperatures during all hours of the seasons. In addition, in the "Stensvand" model calibrated to the data from central Poland, the temperature accumulation lasted for $147 \mathrm{~h}$ after each precipitation. Over half of such periods (54\%) in the years 2005-2008 and 2010-2015 were accounted for in the "All Rain $+\mathrm{LW}+\mathrm{RH}$ " model as hours with observed leaf wetness or high relative humidity, suggesting that a more complicated model may give limited improvement.

The additional "All Rain Proportional" models, in which the degrees accumulated during rain were weighted with the amount of the current rainfall, were tested. The linear and the quadratic relations between the rate of ascospore maturation and the precipitation were examined. Application of the "All Proportional Rain" models does not seem valid as their fit results did not improve the results of the simpler "All Rain" model.

The results of the ascospore maturation model fits to the full set of data available in the study showed the same order of models according to the goodness of fits as the validation and comparison procedure. The four approaches best describing the spore trapping data from central Poland are the "All Rain + LW + RH," the "All Rain + LW," the "All LW" and the "Stensvand" models.

Let us point to the values of $\gamma_{i}$ coefficients of the "All Rain + LW + RH" model. These values should allow to roughly estimate the relative importance of the three main sources of moisture for the ascospore maturation rate. The computed $\gamma_{i}$ values allow to put a hypothesis that as compared to dry hours, the ascospores develop on average fastest in the presence of leaf wetness, slower during rainfalls and most slowly during hours of high relative humidity. The highest value of the $\gamma_{2}$ weight related to leaf wetness may also explain why the "All LW" models gave better fit to the data than the "All Rain" and "All RH" models. Unfortunately, the above hypothesis seems difficult to explain. Each 
of the considered moisture sources leads to the development of ascospores by delivering water to the pseudothecium. Rainfall, due to its pressure, should deliver water to the interior of the pseudothecium in the most effective way. In the case of leaf wetting caused by factors such as fog, dew or rain remnant, the penetration into the pseudothecium should be weaker. The transport of water through the surface of the pseudothecium in the case of high air humidity which does not lead to permanent leave wetness should be even weaker. Hence, it seems that the rain should lead to the fastest ascospore maturation. However, its impact on ascospores may be delayed in time and the major development of spores may occur in the hours following the rainfall, when usually the leaf wetness is observed and therefore it may be accounted for as an effect of leaf wetness.

Final and most important result of the study is such that the level of the uncertainty of the models examined in the study is very high for the data from central Poland, even in the case of models which gave the best fits to the data. The accuracy is not satisfactory if these models are to be used for prediction of ascospore development in future seasons, and the differences between the performance of the compared models become of least importance unless it can be further improved. Therefore, it seems recommended to apply additional methods that could improve the precision of the ascospore maturation models in Polish weather conditions. A few approaches can be used. First, the influence of the biofix definition assumed in the models should be studied in detail. In this study, the temperature accumulation started with the green tip stage of the apple trees in the experimental orchard. This may not be the best selection among the high number of various biofix definitions applied in the literature. For recent discussion on choosing the biofix definition, see Roubal and Nicot (2016). In the same work, the authors proposed to modify the definition of cumulative temperature by using the nonlinear thermal scale. Such approach has already been used for modeling of insect pest (Damos and Savopoulou-Soultani 2012) and other than V. inaequalis fungi development (Xu 1996; Legler et al. 2012; Battilani et al. 2013). The models can be also improved through considering the early spring development of ascospores, which starts before beginning of the airborne ascospores season (Stensvand et al. 2006). Finally, to better predict maturation of ascospores in a particular season, the forecasts of the models, which have been calibrated with the data from earlier years, should be supplemented by laboratory or field analysis of current spore development. The adaptive correcting of the model predictions can be applied, as proposed by Jankowski and Masny (2014).

\section{Conclusion}

The presented study showed that the best description of the ascospore maturation in central Poland is obtained with the mathematical models in which temperature is cumulated during both moist and dry periods. The four approaches best describing the spore trapping data from central Poland are the "Stensvand," the "All LW," the "All Rain + LW" and the "All Rain + LW + RH" models. The presented analysis showed also that all three main sources of moisture: precipitation, leaf wetness and high relative humidity may accelerate ascospore maturation in comparison with periods of dry weather. As indicated, the greatest acceleration of ascospore development is obtained in the presence of leaf wetness, lower during rainfalls and lowest during periods with high relative humidity.

The main result of study is a high range of models' uncertainty for the data from central Poland, shown even for the most effective models. Low accuracy of the models limits their practical application at the current stage of development.

\section{Compliance with ethical standards}

Conflict of interest The authors declare that they have no conflict of interest.

Open Access This article is distributed under the terms of the Creative Commons Attribution 4.0 International License (http://creativeco mmons.org/licenses/by/4.0/), which permits unrestricted use, distribution, and reproduction in any medium, provided you give appropriate credit to the original author(s) and the source, provide a link to the Creative Commons license, and indicate if changes were made.

\section{References}

Alves SAM, Beresford RM (2013) Evaluation of three models for predicting Venturia inaequalis ascospore release in Southern Brazil. N Z Plant Prot 66:303-307

Battilani P, Camardo Leggieri M, Rossi V, Giorni P (2013) AFLAmaize, a mechanistic model for Aspergillus flavus infection and aflatoxin B1 contamination in maize. Comput Electron Agric 94:38-46

Beresford RM (1999) Validation of an ascospore release prediction model for apple black spot (Venturia inaequalis). In: Proceedings of the 52nd New Zealand plant protection conference, pp 148-152

Creemers P, van Laer S (2006) Key strategies for reduction of the dependence on fungicides in integrated fruit production. Phytopathology 39:19-29

Damos P, Savopoulou-Soultani M (2012) Temperature-driven models for insect development and vital thermal requirements. Psyche 2012, Article ID 123405 
Dennis JE, Schnabel RB (1983) Numerical methods for unconstrained optimization and nonlinear equations. Prentice-Hall, Englewood Cliffs, NJ

FAOSTAT (Food and Agriculture Organization Corporate Statistical Database) (2018) Data retrieved 13 Aug 2018, http://www.fao. org/faostat/en/\#data/QC

Gadoury DM, MacHardy WE (1982) A model to estimate the maturity of ascospores of Venturia inaequalis. Phytopathology 72:901-904

Gadoury DM, MacHardy WE, Rosenberger DA (1989) Integration of pesticide application schedules for disease and insect control in apple orchards of the northeastern united states. Plant Dis 73:98-105

Gadoury DM, Seem RC, MacHardy E, MacHardy WE, Rosenberger DA, Stensvand A (2004) A comparison of methods used to estimate the maturity and release of ascospores of Venturia inaequalis. Plant Dis 88:869-874

James JR, Sutton TB (1982a) Environmental factors influencing pseudothecial development and ascospore maturation of Venturia inaequalis. Phytopathology 72:1073-1080

James JR, Sutton TB (1982b) A model for predicting ascospore maturation of Venturia inaequalis. Phytopathology 72:1081-1085

James JR, Sutton TB, Nardacci JF (1981) Evaluation of a New York ascospore maturity model for Venturia inaequalis in North Carolina. Phytopathology 71:1030-1032

Jankowski P, Masny S (2014) An improved method to estimate the uncertainty of models describing the seasonal maturation of Venturia inaequalis ascospores. Can J Plant Pathol 36:456-469

Lacey ME, West JS (2006) Using a Burkard Trap. In: Lacey ME, West JS (eds) The air Spora. Springer, Boston, MA

Legler SE, Caffi T, Rossi V (2012) A nonlinear model for temperature dependent development of Erysiphe necator chasmothecia on grapevine leaves. Plant Pathol 61:96-105

MacHardy WE (1996) Apple scab biology, epidemiology and management. The American Phytopathological Society, St. Paul, Minnesota

MacHardy WE, Gadoury DM (1985) Forecasting the seasonal maturation of ascospores of Venturia inaequalis. Phytopathology 75:381-385

Massie LB, Szkolnik M (1974) Prediction of ascospore maturity of Venturia inaequalis utilising cumulative degree-days. Phytopathology 64:140

Nash JC (1990) Compact numerical methods for computers Linear algebra and function minimisation, 2nd edn. IOP Publishing Ltd, Bristol

R Core Team (2018) R: a language and environment for statistical computing (Internet). Vienna, Austria. http://www.R-project.org/. Accessed 30 Jan 2018
Rossi V, Ponti I, Marinelli M, Giosuè S, Bugiani R (1999) Field evaluation of some models estimating the seasonal pattern of airborne ascospores of Venturia inaequalis. J Phytopathol 147:567-575

Rossi V, Ponti I, Marinelli M, Giosuè S, Bugiani R (2000) A new model estimating the seasonal pattern of air-borne ascospores of Venturia inaequalis (Cooke) Wint. in relation to weather conditions. J Plant Pathol 82:111-118

Rossi V, Giosuè S, Bugiani R (2007) A-scab (Apple-scab), a simulation model for estimating risk of Venturia inaequalis primary infections. EPPO/OEPP Bull 37:300-308

Roubal C, Nicot PC (2016) Apple scab: numerical optimization of a new thermal time scale and application for modelling ascospore release in southern France. Plant Pathol 65:79-91

RStudio Team (2018) RStudio: integrated development for R (Internet). RStudio, Inc., Boston. http://www.rstudio.com/. Accessed 30 Jan 2018

Schwabe WFS, Jones AL, van Blerk E (1989) Relation of degree-day accumulations to maturation of ascospores of Venturia inaequalis in South Africa. Phytophylactica 21:13-16

Shao J (1993) Linear model selection by cross-validation. J Am Stat Assoc 88:486-494

Stensvand A (1993) Apple scab (Venturia inaequalis): on ascospore release, infection, scab warning, and fungicidal control. Ph.D. Dissertation. Agricultural University of Norway

Stensvand A, Gadoury DM, Seem RC, Amundsen T, Falk SP (1998) Some recent advances in epidemiology of apple scab. Abstract presented at the 7th international congress of plant pathology, 1998, Edinburgh

Stensvand A, Eikemo H, Gadoury DM, Seem RC (2005) Use of a rainfall frequency threshold to adjust a degree-day model of ascospore maturity of Venturia inaequalis. Plant Dis 89:198-202

Stensvand A, Eikemo H, Gadoury DM, Seem RC (2006) Climatic conditions prior to green tip of apple affect ascospore maturation in Venturia inaequalis. Pome Fruit Diseases, IOBC/wprs Bull 29:243-247

Wightwick A, Walters R, Allinson G, Reichman S, Menzies N (2010) Environmental risks of fungicides used in horticultural production systems. In: Carisse O (ed) Fungicides. In-Tech, Croatia, pp 273-304

Working H, Hotelling H (1929) Applications of the theory of error to the interpretation of trends. J Am Stat Assoc 24:73-85

Xu XM (1996) On estimating non-linear response of fungal development under fluctuating temperatures. Plant Pathol 45:163-171

Publisher's Note Springer Nature remains neutral with regard to jurisdictional claims in published maps and institutional affiliations. 